\title{
Alice cresceu: uma metáfora das alterações socioculturais na contemporaneidade ${ }^{1}$
}

\author{
Renata Tomaz
}




\section{Resumo}

Este trabalho se propõe a considerar as adaptações feitas no filme Alice no País das Maravilhas (Disney, 2010) como um exercício metodológico para analisar as descontinuidades de dois momentos culturais da modernidade. Levando-se em conta que, tanto a Alice do livro de Lewis Carroll, quanto a Alice do filme de Tim Burton dialogam, cada uma, com a cultura e a sociedade nas quais foram construídas, pretende-se tecer considerações sobre elementos marcantes no funcionamento da cultura contemporânea.

\section{Palavras-chave}

Alice no País das Maravilhas, juvenilização, subjetividades, identidades.

\section{Abstract}

This paper aims to consider the adaptations made in the movie Alice in Wonderland (Disney, 2010) as a methodological exercise to analyze the discontinuities of two cultural moments of modernity. Taking into account that both the Alice of Lewis Carroll's book as Alice of Tim Burton's movie dialogue with culture and society in which they were built, intended to make considerations about striking elements in the functioning of contemporary culture.

\section{Keywords}

Alice in Wonderland, juvenilization, subjectivities, identities. 
"Ah, eu tive um sonho tão esquisito!", disse Alice. E começou a contar à irmã, tanto quanto podia recordar, todas essas estranhas aventuras que vocês acabaram de ler. Quando acabou, sua irmã a beijou e disse:

'Foi um sonho curioso, com certeza, minha querida; mas agora corra para tomar seu chá: já está ficando tarde!'. Então Alice levantou-se e saiu correndo, pensando, enquanto isso, que sonho maravilhoso tinha sido aquele. Mas sua irmã continuou onde estava, com a cabeça apoiada na mão, admirando o pôr-do-sol e pensando na pequena Alice e em todas as suas maravilhosas aventuras (...) Por fim, ela imaginou como seria sua irmãzinha quando, no futuro, se transformasse em uma mulher adulta; e como conservaria, com o avançar dos anos, 0 coração simples e afetuoso da infância".

(Alice no País das Maravilhas, 1865)

As visões do futuro que a irmã de Alice procurava tiveram que esperar mais de um século para tomarem forma. Cento e quarenta e cinco anos após a publicação do clássico de Lewis Carroll ${ }^{3}$, o diretor Tim Burton ${ }^{4}$ lançou sua versão cinematográfica de uma das obras mais conhecidas da literatura inglesa. Nela, a protagonista aparece, com 19 anos, em uma nova visita ao País das Maravilhas. O crescimento de Alice e sua consequente inserção no mundo jovem poderão ser pensados aqui como uma metáfora para analisar as alterações em dois momentos culturais distintos na modernidade. As mudanças de roteiro no longa-metragem, em relação ao livro, não se limitam ao olhar do diretor sobre uma obra original, ao acesso a um incalculável rol de efeitos tecnológicos ou à adaptação da linguagem literária para a cinematográfica. Essas são questões importantes em se tratando de observar as diferenças entre o trabalho de Carroll e o de Burton, mas não fundamentais para o paralelo que proponho entre ambos. Minha intenção é tecer algumas considerações sobre o argumento de que não são apenas nove anos que distinguem a Alice criança da Alice jovem. São

Lewis Carroll era o pseudônimo de Charles Lutwidge Dodgson, professor de matemática da Universidade de Oxford, que publicou, além de Alice no País das Maravilhas (1865) e sua continuação Através do espelho e o que Alice encontrou lá (1872), outros livros infantis, como Sylvie e Bruno (1889) e a sequência Conclusão de Sylvie e Bruno (1893). 
práticas elaboradas por sociedades distintas que dialogam com suas respectivas culturas. Trata-se, portanto, de um exercício metodológico que toma o campo da comunicação como um lugar privilegiado para observar alterações na cultura.

Em sua obra, traduzida para centenas de outros idiomas, Lewis Carroll escreve para crianças, mas não deixa de exibir as contradições de um mundo confrontado com a modernização. O nonsense presente da primeira à última página mostra, no País das Maravilhas, o reflexo de um mundo sem sentido, em que seus habitantes não são mais o que costumavam ser, mas com a possibilidade de serem outros, como afirma Alice. "Quem sou eu, então? Respondam-me primeiro, e então, se eu gostar de ser essa pessoa, voltarei; se não, ficarei aqui embaixo até que eu seja outra" (CARROLL, [1865] 2000, p. 33). O uso do lúdico, do surreal, dos jogos de palavras e da falta de lógica caracteriza o nonsense escolhido por Carroll para produzir esta narrativa.

O autor está entre os maiores nomes do gênero, que ganhou força com a ordenação moderna do mundo, como ferramenta para questionar sua lógica sistematizada, suas catalogações e sua rigidez. Foi por meio do extraordinário, do fantástico e do maravilhoso, presentes no nonsense, que artistas questionaram a "codificação da vida humana", nesse novo mundo (ÁVILA, 1995, p. 20). As respostas confusas diante de perguntas absurdas, os enigmas sem solução e a falta de nexo nos diálogos remeteram o leitor do século XIX às transformações da modernização sentidas particularmente na Europa, onde as sociedades foram convocadas a práticas que as permitissem dominar a natureza, o tempo, os corpos.

Embora o filme também se passe na Inglaterra vitoriana, é no século XXI que ele é produzido, e é com este momento que sua narrativa dialoga. O País das Maravilhas continua com suas criaturas fantásticas, mas com certa coerência. A história tem suas explicações, o que descaracteriza o estilo nonsense do original ${ }^{5}$. Alice não está ali por acaso, ela foi levada de volta para cumprir uma profecia e libertar os habitantes do domínio da Rainha de Copas - tarefa que vai Ihe proporcionar uma jornada a si mesma. 


\section{A Alice de Lewis Carroll e a Alice de Tim Burton}

Num dia de verão, a pequena Alice viu um Coelho Branco correndo no jardim. Ao segui-lo, ela caiu num imenso túnel que a levou até o País das Maravilhas. No local em que chegou, a única chave disponível abria uma pequena porta por onde ela não passava. Após tomar poções e comer bolos, diminuir e esticar, quase se afogar num mar de lágrimas que tinha chorado quando estava gigante, ela passa por diferentes locais e personagens. Abordagens distintas já foram propostas sobre Alice no País das Maravilhas e o nonsense de Lewis Carroll nesta obra (AMORIM, 2005; ÁVILA, 1995; LEITE, 1977). O que se pretende aqui, no entanto, não é "decifrar" o livro, mas buscar elementos que sinalizem sua produção num determinado momento histórico, elementos que possam destacar a sociedade na qual esta obra foi produzida. Para Adorno, o livro de Carroll traz em si esse retrato:

\footnotetext{
Livros infantis como Alice in Wonderland ou Struwwelpeter, perante os quais a pergunta pelo progresso ou pela reação seria ridícula, contêm cifras da história incomparavelmente mais sugestivas do que o grande teatro montado por Hebbel com a temática oficial da culpa trágica, a mudança dos tempos, o curso do mundo e o indivíduo (ADORNO, 1992, p. 133).
}

Para Leite, responsável por uma das adaptações do livro para o português, há um sistema histórico-linguístico em Alice no País das Maravilhas e Através do espelho que traduz o tempo em que estavam inseridos. Ele cita Deleuze para concluir que tal percepção encontrou resposta na sociedade moderna. "Deleuze resumiu a obra de Carroll como um caos/cosmos que teria tudo para fascinar as mentes modernas" (LEITE, 1977, p. 30). Observar a Alice de Lewis Carroll, portanto, neste artigo, é buscar pistas de um tempo específico, onde a questão da mudança, por exemplo, ressoava em diferentes instâncias da vida social. O problema da mudança, no caso de Alice, as sucessivas alterações de tamanho, acompanha a menina em muitas circunstâncias. Ela chega ao ponto de andar com pedaços de cogumelo que a ajudam a regular o tamanho que ora deve ser maior ora menor que sua estatura real. Questionada pela lagarta sobre que 
tamanho gostaria de ter, ela responde: "'Oh, não faço questão do tamanho', respondeu Alice prontamente, 'mas ninguém gosta de ficar mudando tanto assim'" (CARROLL, [1865] 2000, p. 66). Em diferentes momentos, Alice se vê cercada de dilemas sobre o seu tamanho e, portanto, sobre quem é. Interrogada a respeito de sua identidade, ela titubeia em outro diálogo com a lagarta. "'Eu... já nem sei, minha senhora, nesse momento (...). Bem, eu sei quem eu era quando acordei esta manhã, mas acho que mudei tantas vezes desde então'" (CARROLL [1865] 2000, p. 61).

Para alguns autores, a jornada de Alice é uma referência à passagem entre a infância e a adolescência. Segundo Olalquiaga (1998), "a personagem principal fica suspensa no tempo a fim de poder explorar livremente o espaço - os limites de seu corpo - até estar pronta para crescer" (OLALQUIAGA, 1998, p. 25). As tentativas de naturalizar a adolescência como uma fase da vida necessária ao desenvolvimento sadio do indivíduo estavam em franca expansão no final do século XIX e início do século XX. As abordagens psicológicas e médicas apontavam para uma necessidade em cuidar desse indivíduo. Esta foi uma das constatações do psicólogo norteamericano Stanley Hall que, em 1904, lançou o livro Adolescence, em dois volumes de 1.500 páginas. Ele defendia a extensão do período entre a infância e a vida adulta como uma etapa em que o indivíduo desenvolve habilidades para a maturidade e lida com os conflitos emergentes. Neste mesmo ano, foi lançada a peça de teatro Peter Pan, a história do menino que não queria tornar-se adulto.

O tratamento dado a crianças também é uma temática presente no livro. Os diálogos travados por Alice mostram certa impaciência por parte dos demais. O rato demonstra irritação por ela tentar falar sobre sua gatinha Diná; a Lagarta a trata com indiferença, respondendo monossilabicamente; a Pomba desconfia que, ao invés de menina, Alice seja uma serpente perigosa; a Lebre de Março e o Chapeleiro Maluco corrigem-na o tempo todo sobre os seus modos à mesa de chá.

Na opinião de Zschirnt (2006), Alice é um livro que narra o mundo dos adultos através do olhar de uma criança na sociedade vitoriana. Um mundo repleto de adultos tiranos que as crianças tinham de obedecer, mas cujas ordens 
não entendiam. Os personagens sempre têm algo a reclamar sobre Alice. Ela, por sua vez, sempre demonstra obediência, mesmo que isso lhe custe tamanha insatisfação: "'Todo mundo por aqui diz Vamos!'", pensou Alice, enquanto o seguia devagar: 'Nunca recebi tantas ordens em toda a minha vida, nunca!" (CARROLL [1865] 2000, p. 117). Em outra ocasião, ela compara a situação à escola: "'Como estas criaturas dão ordens e obrigam a recitar lições!', pensou Alice. 'Até parece que estou na escola'. Todavia, levantou-se e começou a recitar" (CARROLL [1865] 2000 , p. 127). É só no momento em que Alice se recusa a obedecer a ordens e olha para todas as circunstâncias com um olhar supostamente adulto, que ela retoma sua vida real, fora do País das Maravilhas:

\footnotetext{
"Cortem-Ihe a cabeça!", gritou a Rainha com o máximo de sua voz. Ninguém se moveu. "Quem se importa com você?", disse Alice (ela acabara de crescer até o seu tamanho normal). "Vocês não passam de um maço de cartas!" Naquele momento, todo o baralho voou pelos ares e começou a cair em sua direção: Alice deu um gritinho, meio de susto, meio de raiva, e tentou abatê-los, mas... quando deu por si, estava deitada no barranco com a cabeça no colo de sua irmã (CARROLL [1865] 2000, p. 149).
}

No filme, Alice não se lembra do País das Maravilhas, apenas tem sonhos que a remetem ao local. É numa festa surpresa de noivado que ela avista novamente o Coelho Branco e o segue, caindo logo em seguida no grande túnel. A nova Alice acredita estar num sonho que, mais cedo ou tarde, vai acabar. As poucas vezes em que ela tem que mudar de tamanho não a incomodam como acontece no livro. O que a irrita mesmo são as constantes alegações, por parte das criaturas fantásticas, de que ela precisa cumprir uma profecia e livrar a todos do domínio cruel da Rainha de Copas, matando o monstro Jaguadarte.

O tratamento dado à nova Alice é um pouco diferente do anterior. Há certa impaciência, no início, durante uma discussão entre o Coelho Branco, a rata Mallymkun e os gêmeos Tweedledee e Tweedledum sobre a verdadeira Alice. A lagarta Absolem chega a chamá-la de "menina idiota", como o faz o Chapeleiro no livro, mas com o desenrolar da história, a protagonista logo passa a ser tratada com respeito, atenção e até doçura. Se a pequena Alice em não 
poucos momentos foi um entrave para os personagens do livro, a Alice jovem é investida de confiança, autoridade e autonomia para cumprir sua jornada.

A obediência é outro ponto que não tem força no filme. Bem no início da narrativa, a caminho de sua festa surpresa de noivado, Alice demonstra insolência quando se recusa a usar um espartilho e um collant. No País das Maravilhas, ela não aceita cumprir um destino que não tenha sido pensado ou planejado por ela mesma. Acha absurdo acatar ordens arbitrárias e só cumpre sua tarefa por uma questão pessoal e não para submeter-se à profecia do oráculo. Enquanto no livro são as demais criaturas que monopolizam a autoridade das direções a serem tomadas, no filme Alice assume o papel de heroína e interfere no curso das decisões.

Nem todas as questões tratadas no livro, portanto, encontram eco no filme, onde prevalece o protagonismo da juventude e não da infância. Ele é alinhado com um projeto contemporâneo baseado na autonomia, no exercício da liberdade irrestrita e na capacidade de realizar. A Alice de Tim Burton vai sinalizar outras questões sociais, diferentes daquelas tratadas até aqui. E é utilizando tais sinalizações que este trabalho tece suas considerações a respeito da sociedade contemporânea. Ella Shohat e Robert Stam (2006) acreditam que a arte, em especial o cinema, tem seu mérito social não porque represente o real, mas porque consegue situar discursos historicamente ao estabelecer "uma rede de signos endereçados por um sujeito ou sujeitos constituídos historicamente para outros sujeitos constituídos socialmente, todos imersos nas circunstâncias históricas e nas contingências sociais" (SHOHAT; STAM, 2006, p. 265). É nesse sentido que esse filme nos permite olhar para o momento em que vivemos e ver, por meio das representações presentes nele, particularmente as que alimentam o imaginário juvenil contemporâneo, os elementos que distinguem as culturas em que as duas Alices foram construídas.

\section{Alice cresceu - mas nem tanto}

O livro de Carroll e o filme de Burton fazem representações não só de dois momentos diferentes, mas de sociedades que encontraram formas distintas de 
produzir seus sujeitos. Cada uma, de um modo particular e próprio, forjou meios de os indivíduos se inventarem, construírem um self adequado ao contexto em que se inserem. Particularmente na contemporaneidade, essa produção passa por um regime de liberdade de escolha de elementos constitutivos do sujeito. Tal liberdade pressupõe uma condição autônoma do indivíduo (ROSE, 1996). Nesse contexto cultural, portanto, prevalecem os ideais de independência, maturidade, responsabilidade, autonomia. Por isso, nada mais contemporâneo do que uma Alice que cresceu e cumpriu seu destino habilidosamente.

O crescimento de Alice faz parte de uma dinâmica que pode ser vista em outros produtos culturais contemporâneos. As personagens Mônica e Luluzinha, por exemplo, também se tornaram jovens. As Meninas super poderosas ganharam alguns anos e estão na adolescência ${ }^{6}$. Nem o Pequeno príncipe escapou. Em 2011, a editora Fontanar lançou no Brasil o livro O retorno do jovem príncipe (A. G. Roemmers), que localiza o personagem de Antoine Saint-Exupéry em meio a conflitos da juventude. Além de tornar possível a existência de tais produtos culturais, as sociedades contemporâneas viabilizaram o desenvolvimento de uma faixa etária intermediária, oferecida àquelas crianças que decidem crescer e tornarem-se, também, jovens. A esta categoria de crianças, o aparato midiático tem chamado de pré-adolescentes ou tweens (da palavra inglesa between, que significa entre duas extremidades), designações para aqueles que estariam num movimento de crescimento da infância para a adolescência. Há cada vez mais imperativos que convocam meninos e meninas a amadurecerem e ingressarem na experiência da juventude e num mundo que exige deles constantemente o exercício da liberdade de escolha. O objetivo é de que se constituam sujeitos deste tempo, a partir de uma condição autônoma que Ihes permita agir sobre si mesmos na montagem de um eu adequado.

É importante pontuar, nesse sentido, que esse alargamento da juventude tem provocado a reformulação das estruturas etárias. O Population Reference 
Bureau, dos Estados Unidos, por exemplo, no documento La juventud del mundo 2000, publicado em 2001, redefiniu a faixa etária em que considera a juventude. Determinada pela ONU para as idades entre 15 e 24 anos, foi alterada, com acompanhamento pela própria ONU e pela Organização Mundial de Saúde, para a faixa de 10 a 24 anos. Dados da Organização Ibero-Americana de Juventude mostram que os países da região envolvida também estão revendo suas definições de juventude: El Salvador (7 a 18 anos), Colômbia (12 a 26 anos), Costa Rica (12 a 35 anos), México (12 a 29 anos), Argentina (14 a 30 anos). Isso significa que a mudança cultural está interferindo na definição, mesmo que arbitrária, da estrutura etária (CHILLÁN, 2005). Há quem possa dizer que a escolha de uma Alice jovem não passa de uma estratégia de marketing para atrair, além do público infanto-juvenil, outras faixas etárias, que, aliás, podiam ser vistas às portas das salas de cinema à época da exibição do longa-metragem.

Embora produzido pelos estúdios Disney e baseado numa literatura infantil7, o filme atraiu ampla plateia adulta. Para Borelli (2008), trata-se de um fenômeno visível nas culturas jovens urbanas, cujos produtos não estão restritos ao que ela chama de jovens "tradicionais", pois "suas formas culturais dialogariam com matrizes originárias capazes de restituir referências míticas e de constituir repertórios compartilhados que perpassariam diferentes segmentos" (BORELLI, 2008, p. 68). Entre eles estariam, por exemplo, os geracionais.

Morin chama de juvenilização o processo de estabelecimento e expansão de uma estética jovem na cultura moderna. Trata-se de um esforço constante de atingir não só uma aparência, mas um estilo de vida que remeta à experiência de ser jovem (MORIN, 2005). Para Margulis e Urresti (2000), a modernidade conseguiu estetizar os signos da juventude como paradigmas do que é desejável. Tal simbolização permitiu que a estética juvenil fosse transformada em produtos consumidos não só pelos chamados jovens, mas por outras faixas etárias. Desta forma, permitiu, ainda, que a juventude, enquanto construção social, fosse 
estendida cada vez mais em ambas as direções, disponibilizando os modos de estar jovem no mundo tanto a adultos quanto a crianças.

Segundo Ariès, "passamos de uma época sem adolescência a uma época em que a adolescência é a idade favorita (...) deseja-se chegar a ela e nela permanecer por muito tempo" (ARIÈS, 1981, p. 48). É nesse sentido que se diz que a nova Alice, a de Tim Burton, cresceu, mas nem tanto. Ela chegou à adolescência, mas não deseja sair. Ao voltar do País das Maravilhas, ela se nega ao casamento. Fazendo isso, ela não só adia sua chegada à vida adulta, como mostra que não precisa desse outro estágio para a aquisição de um status social reconhecido e reconhecível na sociedade.

\section{Identidade: de quem é a crise?}

O tema da identidade não ganha no filme de Burton a mesma abordagem que tem no livro de Carroll. Enquanto neste a protagonista se perturba diante das mudanças, chegando a questionar se não teria se tornado outra pessoa, naquele ela afirma saber muito bem quem é. Em meio a incertezas, a pequena Alice só precisava obedecer às instruções que recebia, ainda que a contragosto. Mas a Alice crescida precisa escolher. São suas escolhas durante a jornada que a legitimam como a Alice que todos procuram.

Stuart Hall afirma que a identidade é daqueles conceitos que usamos "sob rasura". Embora tenham sido concebidos numa forma que não atenda mais às solicitações teóricas, são fundamentais para pensar determinadas questões, porém "em suas formas destotalizadas e descontruídas" (HALL, 2009, p. 104). O papel das identidades seria dar-nos segurança ao "alinhar nossos sentimentos subjetivos com os lugares objetivos que ocupamos no mundo social e cultural" (HALL, 2005, p. 12). O que Hall argumenta é que esse sujeito seguro começa a desaparecer no que ele chama de modernidade tardia. Ela é dada a partir de transformações estruturais caracterizadas pela fragmentação das "paisagens culturais" e, consequentemente, das identidades pessoais. A este duplo descentramento, Hall chama de "crise de identidade para o indivíduo" (HALL, 2005, p. 9). Não se 
trata mais da identidade individual, mas de várias identidades assumidas pelo mesmo indivíduo, muitas vezes contraditórias. Nesse sentido, ele defende que não se trata mais de uma identidade unificada, única, permanente, essência do eu. A complexidade moderna questionou esta noção na medida em que crescia a demanda de que os indivíduos exercessem novos papéis sociais.

Hall pensa este cenário a partir da ideia de posição de sujeito. Diante das requisições sociais, cada um é interpelado a se posicionar de maneira adequada. Interpelado a assumir identidades fluidas que, ora são fundamentais e, no instante seguinte, completamente descartáveis, identidades construídas e ofertadas constantemente. A cultura tradicional entregava aos membros das antigas comunidades os caminhos pelos quais eles iriam guiar a própria vida, com objetivos e metas já estabelecidos, enquanto a sociedade contemporânea concede ao indivíduo esta decisão, "um dever disfarçado de privilégio" (BAUMAN, 2008, p. 128). É nesse movimento entre a liberdade de decidir e a obrigatoriedade de fazer escolhas que vivem as novas gerações. São treinadas desde o nascimento a escolherem continuamente a fim de manifestarem nas suas escolhas um eu legítimo, autêntico.

A Alice crescida, construída nessa configuração sócio histórica, não foge a esta dinâmica. Enquanto os personagens apenas discutem entre si se ela é de fato a Alice que estivera ali há nove anos, a protagonista mantém seu objetivo de acordar do sonho. É diante de uma fala do Chapeleiro Maluco que questiona sua autenticidade, que ela revê sua jornada: "Você não é a mesma que era. Você era muito mais... você perdeu sua grandiosidade ${ }^{8}$. Aí dentro ${ }^{9}$ está faltando algo". É esta afirmação que a intriga, ou seja, a acusação de não estar sendo ela mesma, de não ser autêntica. Tal virtude é altamente cotada na contemporaneidade e entendida não como um traço inato da personalidade, mas como uma construção possível por meio de escolhas que demonstrem coerência entre o estilo de vida e as crenças e valores apropriados (FREIRE FILHO, 2007). Daí para frente, Alice se (re)posiciona e se identifica com a heroína que está sendo a todo tempo solicitada a ser. 
Diante da iminência do Dia Colossal, aquele em que o monstro deveria ser destruído, Alice ouve da Rainha Branca: "A escolha deve ser sua, porque quando enfrentar aquela criatura irá sozinha". Sentido-se incapaz de exterminar o Jaguadarte, Alice se desespera e pede ajuda a Absolem, ao que este responde: "Não posso ajudá-la quando nem você sabe quem é, menina idiota". Ela, então, rebate a lagarta, dizendo: "Não sou idiota. Meu nome é Alice, eu moro em Londres. Minha mãe se chama Hellen e minha irmã Margareth. Meu pai era Charles Kingsley. Ele teve uma visão de viajar pelo mundo e nada o deteve. Eu sou filha dele. Sou Alice Kingsley". Mas nenhuma dessas credenciais identitárias era suficiente naquele momento. Não basta ser o que sua família determinou. É preciso ser ela mesma, conhecer-se intimamente.

Ao dizer que Alice não sabia quem era, a lagarta Absolem instigava a olhar não para sua superfície, mas para o seu interior. A preocupação em conhecer-se e interpretar-se é questão central na modernidade tardia. Para Lipovetsky (1988), diante da falência, da desilusão e do declínio da vida pública, descreditada pelo fracasso de um projeto progressivo de modernidade, apenas a vida privada sai vitoriosa. Esse movimento da vida pública para a vida privada tornou possível o desenvolvimento de toda uma tecnologia de subjetivação evidenciada, na opinião do autor, pela "proliferação dos organismos psi, técnicas de expressão e de comunicação, meditações e ginásticas orientais. A sensibilidade política dos anos sessenta deu lugar a uma sensibilidade terapêutica" (LIPOVETSKY, 1988, p. 51). Ele chama de hiperinvestimento as constantes investidas dos indivíduos em si mesmos, dando força e forma à tarefa de autorrealização.

A Alice crescida, portanto, é chamada a uma jornada a si mesma. A ajuda para tanto vem do próprio Absolem, definido pelos gêmeos Tweedledee e Tweedledum como "o sábio", "o absoluto". É da lagarta a instrução que vai dar a Alice a certeza de que ela é a pessoa certa para destruir o monstro. Sua figura lembra os expertos e peritos da cultura contemporânea. Eles ensinam os indivíduos a fazerem escolhas e tomarem suas decisões de forma acertada, apresentando um elenco de comportamentos condizentes com uma mentalidade de governo que opera à distância por meio de 
indivíduos autodisciplinados (FREIRE FILHO, 2007). Absolem ajuda Alice a lembrarse de quem é de fato, a menina que estivera ali há nove anos. Este entendimento permite que ela enfrente o monstro e o mate após dizer a si mesma a frase: "Eu posso vencer o Jaguadarte". Depois de cumprir a profecia e voltar para casa, Alice afirma que vai permanecer solteira e encontrar algo de útil para fazer na vida. Isso embora estivesse numa sociedade em que uma mulher, sobretudo jovem, jamais teria direito a escolher casar ou não. Ela se torna sócia do ex-quase-sogro e embarca em um navio para a China a fim de fechar um negócio. Nada mais contemporâneo.

\section{Considerações finais}

Essa análise nos permite comprovar a pertinência do uso de produtos culturais para pensar as alterações operacionalizadas pela cultura nas sociedades. Também corrobora a comunicação como um lugar privilegiado para refletir os meios pelos quais os sujeitos podem se constituir em um dado momento. Tal entendimento se afirma pelo fato de a Alice de Lewis Carroll e a Alice de Tim Burton dialogarem, cada uma, com a cultura e a sociedade nas quais foram forjadas. A primeira, num universo repleto de mudanças, de novas configurações e códigos para serem decifrados. Nele, cada um precisava submeter-se a normas e regras a fim de atingir a estatura média, correta, diante das demandas sociais. A segunda, num ambiente diluído, fluido em que "à norma dirigista ou autoritária substituiu-se a norma 'indicativa, flexível, os 'conselhos práticos', as terapias 'por medida'"' (LIPOVETSKY, 1988, p. 60).

Nesse caso, o eu é lugar prioritário de investimentos. Enquanto uma precisa obedecer para fazer o caminho de volta à sua casa, a outra precisa escolher para fazer o caminho que vai levá-la a si mesma. A presença de uma Alice jovem, em vez de criança, sinaliza para o protagonismo crescente da juventude, não apenas como uma fase socialmente construída da vida, mas como um estilo de vida, um modo de estar e ser no mundo. Nesse sentido, as adaptações às quais o longa-metragem foi submetido estão diretamente relacionadas às transformações experimentadas ao longo da modernidade. Trata-se, portanto, de um filme mais fiel ao seu tempo do que a sua obra de origem. 


\section{Referências}

ADORNO, T. Mínima moralia. São Paulo: Ática, 1992.

AMORIM, L. M. Tradução e adaptação: encruzilhadas da textualidade em Alice no País das Maravilhas, de Lewis Carroll, e Kim, de Rudvard Kolina. São Paulo: Unesp, 2005.

ARIÈS, P. História social da criança e da família. 2a. ed. Rio de Janeiro: Zahar, 1981.

ÁVILA, M. Rima e solução: a poesia nonsense de Lewis Carroll e Edward Lear. São Paulo: Annablume, 1995.

BAUMAN, Z. Vida para consumo: a transformação das pessoas em mercadorias. Rio de Janeiro: Zahar, 2008.

BORELLI, S. H. S. "Cenários juvenis, adultescências, juvenilizações: a propósito de Harry Potter". In: BORELLI, S. H. S., FREIRE FILHO, J. (orgs.). Culturas juvenis no século XXI. São Paulo: Educ, 2008, p. 59-78.

CARROLL, L. Alice no País das Maravilhas. São Paulo: Sol, 1865 (2000).

CHILLÁN, Y. "Morfologia e cenários das políticas públicas para a juventude: uma leitura com base no perfil regional e na expectativa latino-americana". In: THOMPSON, A. A. (org.). Associando-se à juventude para construir o futuro. São Paulo: Peirópolis, 2005, p. 59-105.

FREIRE FILHO, J. "Poder de comprar: pós-feminismo e consumismo nas páginas da revista Capricho". In: MÉDOLA, A. S. D.; ARAÚJO, D. C.; BRUNO, F. (orgs.) Imagem, visibilidade e cultura midiática. Livro da XV Compós. Porto Alegre: Sulina, 2007, p. 113-140. 
HALL, S. A identidade cultural na pós-modernidade. Rio de Janeiro; DP\&A, 2005. . Quem precisa da identidade? In: SILVA, T. T. (org.). Identidade e diferença. 9a. ed. Petrópolis/RJ: Vozes, 2009. p. 103-133.

LEITE, S. U. "O que a tartaruga disse a Lewis Carroll". In: CARROLL, L. Aventuras de Alice no País das Maravilhas, através do espelho e o que Alice encontrou lá. São Paulo: Summus, 1977.

LIPOVETSKY, G. A era do vazio. Lisboa: Relógio d'água, 1988.

MARGULIS, M.; URRESTI, M. "La juventud es más que una palabra". In: MARGULIS, M. La juventud es más que una palavra. Buenos Aires: Biblios, 2000, p. $13-30$.

MENA, F. "Quis ser fiel ao legado de 'Alice', não à história, diz Tim Burton". Folha de S. Paulo. Ilustrada. 09 mar. 2010. Disponível em: http://www1.folha.uol. com.br/folha/ilustrada/ult90u704221.shtml. Acessado em: 05 dez. 2012.

MORIN, E. Cultura de massas no século XX: o espírito do tempo 1. Neurose. 9a. ed. Rio de Janeiro: Forense Universitária, 2005.

OLALQUIAGA, C. Megalópolis: sensibilidades culturais contemporâneas. São Paulo: Studio Nobel, 1998.

ROSE, N. Inventing our selves. Cambridge: Cambridge University Press, 1996.

SHOHAT, E. \& STAM, R. Crítica da imagem eurocêntrica: multiculturalismo e representação. São Paulo: Cosac Naify, 2006.

ZSCHIRNT, C. Livros: tudo que você não pode deixar de ler. São Paulo: Globo, 2006. 